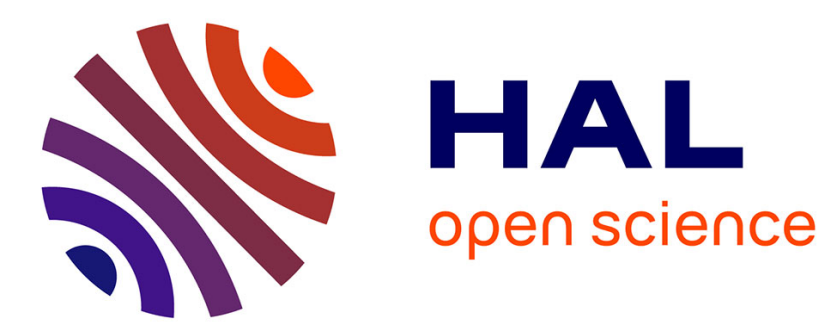

\title{
MÖSSBAUER EFFECT STUDY OF NATURAL EGYPTIAN CHALCOPYRITE
}

\author{
N. Eissa, H. Sallam, M. El-Ockr, E. Mahmoud, S. Saleh
}

\section{To cite this version:}

N. Eissa, H. Sallam, M. El-Ockr, E. Mahmoud, S. Saleh. MÖSSBAUER EFFECT STUDY OF NATURAL EGYPTIAN CHALCOPYRITE. Journal de Physique Colloques, 1976, 37 (C6), pp.C6793-C6-796. 10.1051/jphyscol:19766167 . jpa-00216689

\section{HAL Id: jpa-00216689 https://hal.science/jpa-00216689}

Submitted on 1 Jan 1976

HAL is a multi-disciplinary open access archive for the deposit and dissemination of scientific research documents, whether they are published or not. The documents may come from teaching and research institutions in France or abroad, or from public or private research centers.
L'archive ouverte pluridisciplinaire HAL, est destinée au dépôt et à la diffusion de documents scientifiques de niveau recherche, publiés ou non, émanant des établissements d'enseignement et de recherche français ou étrangers, des laboratoires publics ou privés. 


\title{
MÖSSBAUER EFFECT STUDY OF NATURAL EGYPTIAN CHALCOPYRITE
}

\author{
N. A. EISSA, H. A. SAllAM, M. M. EL-OCKR, E. A. MAHMOUD and S. A. SAleH (*) \\ Mössbauer Laboratory, Faculty of Science, Al-Azhar University, Cairo, Egypt
}

\begin{abstract}
Résumé. - Des échantillons de chalcopyrite naturel de la région Umm Somuki du Désert Egyptien de l'Est ont été étudiés en utilisant l'effet Mössbauer (ME) et la diffraction de rayons X, pour identifier les phases différentes et les changements de phase des minéraux et pour étudier les propriétés physiques de ces minéraux. Le spectre Mössbauer (ME) a montré l'existence de phases $\alpha, \beta$ et $\gamma$ de chalcopyrite en plus de la pyrite. Les paramètres Mössbauer ont indiqué que le Fer dans le chalcopyrite était sous forme trivalente et soumis à une liaison de covalence. Les phases $\alpha$ et $\beta$ ont été trouvées sous forme magnétique tandis que la phase $\gamma$ est paramagnétique. La température de transformation et la production de chaque phase ont été identifiées.
\end{abstract}

Abstract. - Natural chalcopyrite samples from Umm Samuki region in Eastern Egyptian Desert were studied using Mössbauer Effect (ME) and X-ray diffraction in order to identify the different phases and phase changes occuring in the ore and to investigate the physical properties of the mineral. The ME spectra showed the existence of $\alpha, \beta$ and $\gamma$ phases of chalcopyrite in addition to pyrite. The ME parameters indicated that the iron in chalcopyrite was in the trivalent state and bonded covalently. The $\alpha, \beta$-phases were found to be in a magnetic state, while the $\gamma$ phase was paramagnetic. The transformation temperature and the product of each phase was identified.

1. Introduction. - The previous ME studies on natural and synthetic samples of chalcopyrite $\left(\mathrm{CuFeS}_{2}\right)$ did not give complete interpretation for the experimental results. Aramu et al. [1] obtained a doublet at both room and liquid nitrogen temperatures. From the values of isomer shift they suggested that chalcopyrite has the resonance structure.

$$
\mathrm{Cu}^{+} \mathrm{Fe}^{+3}\left(\mathrm{~S}^{-2}\right)_{2} \rightleftharpoons \mathrm{Cu}^{-3} \mathrm{Fe}^{-}\left(\mathrm{S}^{+2}\right)_{2} \text {. }
$$

For a natural chalcopyrite Raj et al. [2] obtained a magnetic hyperfine pattern with $H=325 \mathrm{kOe}$ and with temperature independent quadrupole splitting which led then to assure that chalcopyrite is a covalent compound in which the iron atom is in the trivalent state. They also showed that the sample was decomposed befor $300^{\circ} \mathrm{C}$. Herrenberg [3] obtained a spectrum of two extra central peaks beside the six lines pattern characteristic of the magnetic phase. She did not give any interpretation about this doublet. Piekoszecosh et al. [4] studied a natural sample of chalcopyrite and showed that chalcopyrite is decomposed at $600 \mathrm{~K}$. Gre. enwood et al. [5] and Frank [6] studied samples which showed magnetic patterns at both room and liquid nitrogen temperatures. So it was decided in the present work to carry out a complete study using X-ray diffraction and ME spectroscopy in order to identify the different phases and iron forms present in the Egyptian chalcopyrite ore, and to study the Ithermal decomposition and products of each phase. The

${ }^{*}$ ) Chemistry Department, Egyptian Archaeology Center, Cairo. second aim is to interpret the previous results in the literature according to these different phase.

2. Experimental procedure. - Natural chalcopyrite samples were collected from Umm samuki region in the Eastern Egyptian Desert. The ME absorber, were prepared from these natural samples to give a thickness of $\sim 20 \mathrm{mg}$ iron $/ \mathrm{cm}^{2}$. The ME spectra were measured by a spectrometer of the constant acceleration type which was coupled to 512 multichannel analyser. The source was $10 \mathrm{mC} \mathrm{Co}{ }^{57}$ in $\mathrm{Cr}$ matrix.

3. Results and discussion. - The ME spectra of one sample consists of a magnetic hyperfine pattern at both room and liquid nitrogen temperatures as shown in figure 1 . The X-ray diffraction studies of

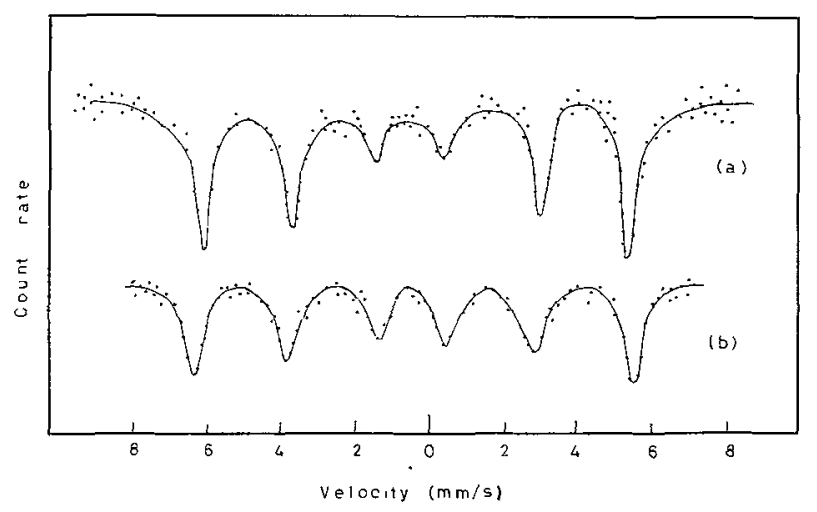

Fig. 1. - Mössbauer spectra of chalcopyrite (sample 1) $(a)$ at room temperature, $(b)$ at liquid nitrogen temperature. 
this sample showed the presence of $\alpha$ - and $\beta$-phases of chalcopyrite in addition to sphalerite $(\beta-\mathrm{ZnS})$, sellite $\left(\mathrm{MgF}_{2}\right)$ and some non-iron silicate compounds. The shape of the Mössbauer - line cannot permit the separation of the two phases of chalcopyrite, i. e. the ME parameters are nearly the same.

The spectra of another sample from the same locality showed a central doublet at both room and liquid nitrogen temperatures beside the magnetic pattern which was obtained for the first sample. The broadening of the absorption peaks of the central doublet together with the asymmetry of the intensity of its lines indicate the superposition of more than one hyperfine pattern in this region. This was confirmed by the X-ray diffraction results of this sample which showed the presence of $\alpha, \beta$, and $\gamma$-phases of chalcopyrite as well as pyrite $\left(\mathrm{FeS}_{2}\right)$ beside the non-iron compounds. These results means that the $\alpha$ and $\beta$ phases of chalcopyrite are in magnetic states at room temperature while the $\gamma$-phase and pyrite are in the paramagnetic state till liquid nitrogen temperature. These results indicate also that Egyptian chalcopyrite ore contains all the phases at which chalcopyrite can exist together with some pyrite. The formation of the three phases in the ore can throw some light on the geochemical conditions under which the Egyptian chalcopyrite ore was formed. Chalcopyrite should have been formed under high temperature and on cooling separation of phases may occur under favourable conditions [7].

According to Pauling and Brockway [8] the iron atom in chalcopyrite $\left(\mathrm{CuFeS}_{2}\right)$ is coordinated by tetrahedron of sulphur atoms with interatomic distances $\mathrm{Fe}-\mathrm{S}=2.20 \AA$. It is known [8-10] also that chalcopyrite can exist in three phases : $\alpha-\mathrm{CuFeS}_{2}$ which is tetragonal with $a=5.25, c=10.32 \AA$, $\beta-\mathrm{CuFeS}_{2}$ which is cubic with $a=10.60 \AA$ and $\gamma$-CuFeS ${ }_{2}$ which is tetragonal with $a=10.58, c=$ $5.37 \AA$. Magnetically $\alpha$-is antiferromagnetic and $\beta$ - is ferromagnetic, but no informations were given about the magnetic properties of the $\gamma$-phase. Combining the results of the present measurements with these informations, one can interpret the discrepancies in the previous results [1-6]. The zeeman pattern obtained by Raj et al., Pickoszecoch et al., Greenwood et al. and Frank was due to either $\alpha$-, or B-chalcopyrite. The values of the ME parameters obtained in the present work (Table I) for these two phases are nearly in agreement with those obtained by Frank [6]. The quadrupole splitting which has a value of $0.08 \mathrm{~mm} / \mathrm{s}$ at both room and liquid nitrogen temperatures is independent on temperature. This independency suggests that iron in chalcopyrite is in the trivalent state in high symmetry site. The observed value of the internal magnetic field $(360 \mathrm{kOe})$ is less than those of ionic $\mathrm{Fe}^{+3}$ compounds $(\sim 500 \mathrm{kOe})$ but it is comparable with the value obtained [11] for $\mathrm{KFeS}_{2}$ where $\mathrm{Fe}$ atom is in the trivalent state and bonded covalently. This is in agreement with the conclusion by Raj et al. [2] for the iron atom in chalcopyrite. How ever varied results $[9,12]$ have been obtained in attempts to determine the valency states of copper and iron in chalcopyrite. Neutron diffraction experiments [9] indicate that copper and iron are in mono and trivalent states respectively. Measurements of X-ray absorption edges [12] suggest that copper is present in two valence states, so that resonance between $\mathrm{Cu}^{+} \mathrm{Fe}^{+3}$ and $\mathrm{Cu}^{+2} \mathrm{Fe}^{+2}$ may be

TABLE I

Mössbauer parameters for Chalcopyrite

(1)

$$
\alpha, \overline{\mathrm{B}-\mathrm{CuFeS}}{ }_{2}
$$

(2) $\left\{\begin{array}{l}\alpha, \mathrm{B}-\mathrm{CuFeS}_{2} \\ \gamma-\mathrm{CuFeS}_{2} \\ \mathrm{FeS}_{2}\end{array}\right.$

(2) $\left\{\begin{array}{l}\alpha, \mathrm{B}-\mathrm{CuFeS}_{2} \\ \gamma-\mathrm{CuFeS} \\ \mathrm{FeS}_{2}\end{array}\right.$

Chalcopyrite

Chalcopyrite

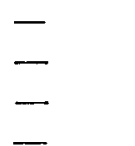

$\begin{array}{cc}\text { Temperatures } & \text { I. } S . \\ \text { mm/s } \\ \text { R. T. } & 0.40 \pm 0.08 \\ \text { L. N. } & 0.40 \pm 0.08 \\ & 0.36 \pm 0.08 \\ \text { R. T. } & 0.12 \pm 0.04 \\ & 0.40 \pm 0.04 \\ & 0.36 \pm 0.08 \\ \text { L. N. } & 0.16 \pm 0.04 \\ & 0.44 \pm 0.04 \\ \text { R. T. } & 0.55 \pm 0.03 \\ \text { L. N. } & 0.87 \pm 0.03 \\ \text { R. T. } & 0.26 \pm 0.02 \\ \text { R. T. } & 0.49 \\ \text { L. N. } & 0.63 \\ \text { R. T. } & 0.26 \pm 0.02 \\ \text { L. N. } & 0.28 \pm 0.02 \\ \end{array}$

Q.S.

$\mathrm{mm} / \mathrm{s}$

$0.08 \pm 0.04$

$0.08 \pm 0.04$

$0.08 \pm 0.04$

$0.40 \pm 0.08$

$0.64 \pm 0.04$

zero \pm 0.08

$0.48 \pm 0.08$

$0.56 \pm 0.04$

$0.60 \pm 0.03$

$0.40 \pm 0.03$

$0.05 \pm 0.02$

-

zero \pm 0.01

zero \pm 0.02

$\begin{gathered}\Gamma \\ \mathrm{mm} / \mathrm{s}\end{gathered}$
$0.56 \pm 0.08$
$0.64 \pm 0.08$
$0.72 \pm 0.08$
$0.48 \pm 0.08$
$0.48 \pm 0.04$
$0.80 \pm 0.08$
$0.56 \pm 0.08$
$0.56 \pm 0.04$


0.32
0.34

Reference

Present work

Present work

zero $\quad 0.48 \pm 0.04$

$366 \pm 5 \quad 0.80 \pm 0.08$

zero $\quad 0.56 \pm 0.04$

zero

zero

$\pm 10$

368

$352 \pm 3 \quad 0.32$

$370 \pm 5 \quad 0.34$

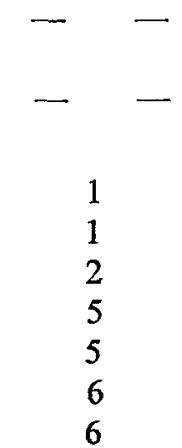

$I . S$. is relative to Fe metal. 
presumed. Whereas earlier workers using cryoscopic and electrolytic method, designated that both metals are divalent.

The disagreement in the values of the ME parameters in some previous results with ours may be due to the non-purity of the mineral in their samples since chalcopyrite is often intergrown with other copper and iron sulphides [13]. On the other hand the doublet obtained by Aramu et al. [1] and that obtained by Herzenberg [3] beside the magnetic pattern may be due to the $\gamma$-phase of chalcopyrite.

The spectrum due to $\gamma-\mathrm{CuFeS}_{2}$ alone in our sample could be separated by measuring a sample of natural Egyptian pyrite from the same locality. Applying the peeling off method [14] and assuming equal line widthes for pyrite and $\gamma$-chalcopyrite the parameters of both pyrite and $\gamma-\mathrm{CuFeS}_{2}$ was determined (Table I). The ME parameters obtained for $\gamma$-chalcopyrite are I. $S .=0.12 \mathrm{~mm} / \mathrm{s}$ and $Q . S .=0.40 \mathrm{~mm} / \mathrm{s}$. These values are not in agreement with those obtained by Aramu et al. [1]. On the other hand it is clear (Table I) that the values obtained by Aramu et al. are in agreement with those characteristic for pyrite. So their sample could have been pyrite. The low value of $I$. $S$. obtained in this work indicates also that $\gamma-\mathrm{CuFeS}_{2}$ is a covalent compound.

The sample which contains the three phases of chalcopyrite and pyrite was subjected to the thermal decomposition process. Different specimens were heated in steps of $50^{\circ} \mathrm{C}$ up to $600^{\circ} \mathrm{C}$ during two hours, and then annealed to the room temperature slowly. The ME spectra for some of the measured samples are shown in figure 2 . It was found from the measured spectra that all components are nearly constant up to $250^{\circ} \mathrm{C}$. This means that this temperature is not sufficient to cause any chemical or phase transformations. At $300^{\circ} \mathrm{C}$ a new magnetic hyperfine pattern started to appear with a decrease in the intensity of the $\alpha$ and $\beta$-phases. The values of the ME parameters of the new magnetic pattern $(H=510 \pm 5 \mathrm{kOe}, Q . S .=0.32 \pm 0.08 \mathrm{~mm} / \mathrm{s}$ and I. $S .=0.44 \pm 0.08 \mathrm{~mm} / \mathrm{s}$ ) are characteristic of the iron oxide $\alpha-\mathrm{Fe}_{2} \mathrm{O}_{3}$. So it can be suggested that at $300{ }^{\circ} \mathrm{C}$ the $\alpha$, and $\beta$-phases of chalcopyrite starts to decompose to $\alpha-\mathrm{Fe}_{2} \mathrm{O}_{3}$. At $450{ }^{\circ} \mathrm{C}$ the component due to pyrite disappeared with corresponding increase in the intensity of the next magnetic pattern, due to $\alpha-\mathrm{Fe}_{2} \mathrm{O}_{3}$. To confirms that pyrite was decomposed to $\alpha-\mathrm{Fe}_{2} \mathrm{O}_{3}$ at 450 , the $\mathrm{ME}$ spectrum of a pure natural pyrite sample was measured after heating the sample to $450^{\circ} \mathrm{C}$ and the same magnetic pattern was obtained. The ME spectrum of the same sample at liquid nitrogen temperature showed change in the sign of the quadrupole splitting due to Morin transition [15]. This insure that the magnetic pattern which was

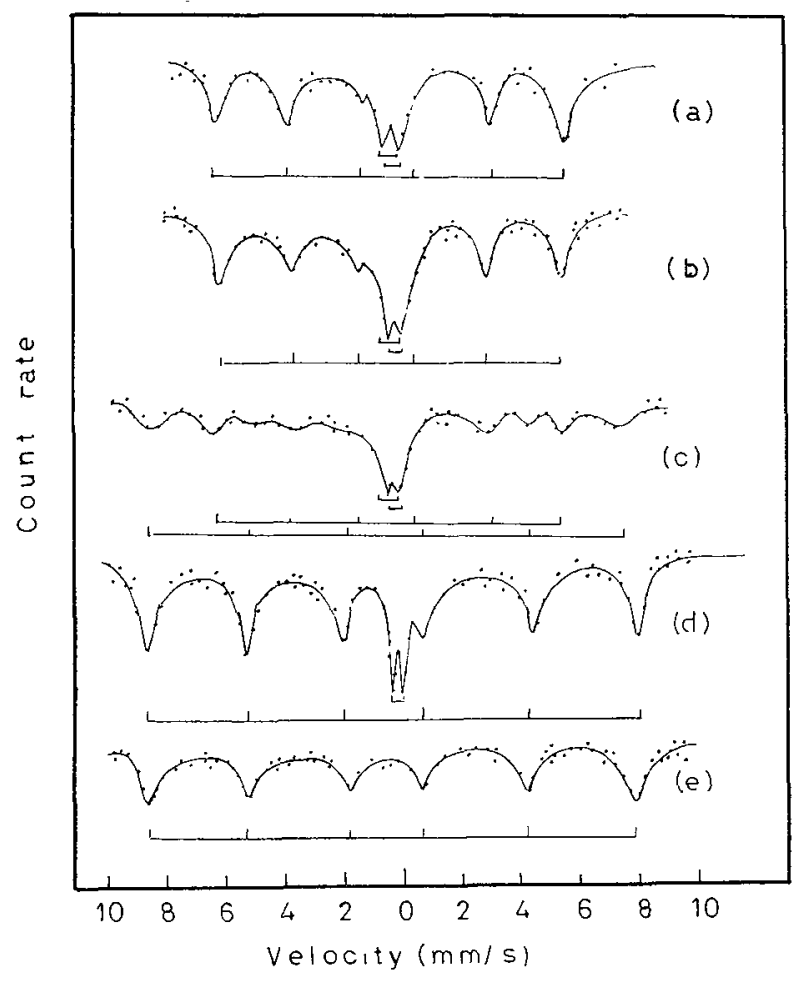

FIG. 2. - Mössbauer spectra of chalcopyrite (sample 2) at different temperatures $(a)$ at liquid nitrogen temperature, (b) at room temperature, (c) at $300^{\circ} \mathrm{C},(d)$ at $450^{\circ} \mathrm{C}$ and (e) $550^{\circ} \mathrm{C}$

obtained during the decomposition of pyrite and chalcopyrite is due to the formation of $\alpha-\mathrm{Fe}_{2} \mathrm{O}_{3}$. At $550^{\circ} \mathrm{C}$ the $\gamma$-phase of chalcopyrite decomposed also to $\alpha-\mathrm{Fe}_{2} \mathrm{O}_{3}$.

4. Conclusion. - From the above results it can be concluded that Egyptian chalcopyrite ore contains the different phases $\alpha, \mathbf{B}$, and $\gamma-\mathrm{CuFeS}_{2}$, pyrite, sphalerite and sellite. The existence of these compounds can give an idea about the geochemical conditions under which chalcopyrite was formed.

The iron in chalcopyrite is in the trivalent state and is bonded covalently.

The $\alpha$-phase is antiferromagnetic, the $\beta$-phase is ferromagnetic and the $\gamma$-phase is paramagnetic till liquid nitrogen temperature.

The $\alpha$ and $\beta$-phases of chalcopyrite decompose to $\alpha-\mathrm{Fe}_{2} \mathrm{O}_{3}$ in the range between $300{ }^{\circ} \mathrm{C}$ to $400^{\circ} \mathrm{C}$, the $\gamma$-phase decomposes to $\alpha-\mathrm{Fe}_{2} \mathrm{O}_{3}$ between 500 and $550{ }^{\circ} \mathrm{C}$ and pyrite decomposes to $\alpha-\mathrm{Fe}_{2} \mathrm{O}_{3}$ at about $450^{\circ} \mathrm{C}$.

The obtained results of the different phases of chalcopyrite can remove the ambiguity in the previous results. 


\section{References}

[1] Aramu, F. Bressani, T. and Manca, P., Nuovo Cimento LIB M. 2 (1967) 370.

[2] Raj., D., Chandria, K. and Puri, S. P., J. Phys. Soc. Japan 24 (1968) 39.

[3] HerzenberG, C. L., Nuovo Cimento LIIIB (1968) 516.

[4] Piekoszewsh, J., Suwalski, J. and Ligenza, S., Phys. Stat. Sol. 21 (1968) 99.

[5] Greenwood, N. N. and Whitrield, H. J., J. Chem. Soc 3A (1968) 1667.

[6] Frank, E., Nuovo Cimento LVIIIB (1968) 407.

[7] Buerger, M. J., Proc. Internat. Symp. On Reactivity of solids, Gothenburg pt. 1 (1954) 225.

[8] Pauling, L. and Brockway, L. O., Z. Krist. 82 (1932) 188.
[9] Donnay, G., Carliss, L. M., Donnay, J. D. H., Elliot, N. and Hastings, J. M., Phys. Rev. 112 (1958) 1917.

[10] Hiller, J. E. and Probsthain, K., Z. Krist., 108 (1956) 108.

[11] Kerler, W., Neverwirth, W., Fluck, E. Pkulrn and Zimerman, B., Fur. Phys. 173 (1963) 321.

[12] Kurylenko, X. C., Bull. Soc. Franc. Min. Crist. 65 (1942) 45.

[13] Fleischer, M., Econ. Geol. 50th aniv., pt. 11 (1955) 970.

[14] Siegrahn, K., Alpha, Beta and Gamma spectroscopy (North Holland Pub. Comp.) 1965.

[15] Kunding, W. Bommel, H., Constabaris, G. and LindQUIST, R. H. Phys. Rev., 142 (1966) 327. 